\title{
Biosynthesis and Characterization of Silver Nanoparticles (SNPs) by using Leaf Extracts of Ocimum Sanctum L (Tulsi) and Study of its Antibacterial Activities
}

\author{
Birendra K Bindhani $^{1 *}$ and Ashok K Panigrahi \\ ${ }^{1}$ School of Biotechnology, KIIT University, Bhubaneswar, Odisha, India \\ ${ }^{2}$ Department of Botany, Berhampur University, Berhampur, Odisha, India
}

\begin{abstract}
The present study aimed to synthesis of SNPs (Silver Nanoparticles) or (Green-Silver) in aqueous medium using leaf extracts of Ocimum sanctum L. The synthesized silver nanoparticles (SNPs) were characterized by the different techniques such as UV-vis Spectrophotometer, XRD, FTIR and TEM. The synthesis of silver nanoparticles were confirmed due to the SPR optical absorption band peak at $\sim 40 \mathrm{~nm}$ by UV-vis spectrophotometer, nearly $15-45 \mathrm{~nm}$ in diameter with spherical in shape by TEM, high crystalline with the Bragg peaks of (111), (200), (220) and (311) plane as the predominant orientation by XRD and FTIR confirmed the presence of methoxy and allyl groups in SNPs. The reduction of Ag metal ions was performed due to the presence of various types of anti-oxidants in the leaves of Ocimum sanctum $\mathrm{L}$. and each having a unique structure and functions. The formations of silver nanoparticles through aqueous medium were fairly stable and which can be incubated up to 4 months in refrigerator. At last, the antimicrobial activities of AgNPs were evaluated using different bacteria strain. It was found that, this biosynthesizing of silver nanoparticles may inhibit the all types of bacterial pathogenic organisms competently. This recent research study opens an innovative design to progress our understanding of how SNPs behave can be optimized to improve human antimicrobial activities.
\end{abstract}

Keywords: Biosynthesis; Ocimum sanctum L (Tulsi); Silver nanoparticles (SNPs); Antibacterial activity

\section{Introduction}

In the last decade there had been tremendous developments in nanotechnology science, which resulted in the establishment of several new techniques for research. Nanotechnology has achieved the rate of combing all living organisms-plants, animal and microorganisms [1-7]. It includes multidisciplinary research interest like Biochemistry, Material Science, Polymer Science and etc. This has made nanotechnology indispensible in such diverse field as agriculture, industry, medicine, forestry and environmental management [8-12]. The nanoscale materials with zero-valent iron have accepted major significance for environmental remediation due its abundant, ecofriendly, low cost and non-toxic [13-18].

Now a day, the use of different types of medicinal plants has been increase by traditional medical practitioners for the treatments of various types of diseases. The most common and important medicinal plant i.e., Ocimum sanctum L. which have different medicinal properties such as anticancer, antimicrobial, cardio-protective, antidiabetic, analgesic, antispasmodic, antiemetic, hepatoprotective, antifertility, adaptogenic and diaphoretic actions. The active constituent of leave of the Ocimum sanctum L. is Eugenol (1-hydroxy-2-methoxy-4allylbenzene) which is mainly responsible for the therapeutic potentials of cardiovascular system, urinary system, reproductive system, immune system, gastric system, blood biochemistry, central nervous system and also significance in various ailments in modern medicine [19-21].

Now a days, green synthesis of SNPs were carried out by using different parts of plant extracts, even though biosynthesis of SNPs by plants such as Solanum xanthocarpum L. Berry [22], tea leaf [23], Callicarpa maingayi stem bark [24], Bauhinia variegate L. [25], Terminalia chebula [26], Trachyspermum ammi and Papaver somniferum [27], Hevea brasiliensis [28], Memecylon edule [29], Aloe vera [30] have been reported. The use of SNPs have already been reported as anti-angiogenesis [31], anti-inflammatory [32], anti-platelet activity [33], anti-bactarial [34] and anti-viral [35]. The improvement of SNPs are rapidly increasing in different fields and it may use in food packaging, coating for bio-labeling, antimicrobial agent, solar energy and drug delivery [36-38].

The purpose of this research work is to provide information on the recently discovered green synthesis process of SNPs using leaf extracts of Ocimum sanctum L. and reduction of $\mathrm{Ag}^{+}$ions to $\mathrm{Ag}^{0}$ nanoparticles from $\mathrm{AgNO}_{3}$ solution within 45 minutes of reaction time at $80^{\circ} \mathrm{C}$ temperature. The size of SNPs can be managed from the range of 5 $\mathrm{nm}$ to $40 \mathrm{~nm}$ by changing the concentration of both leaf extracts and $\mathrm{AgNO}_{3}$. Further, this research study opens an innovative design to progress our understanding of how SNPs behave can be optimized to improve human antimicrobial activities particularly against bacteria.

\section{Materials and Methods}

Silver Nitrate $\left(\mathrm{AgNO}_{3}\right)$ and Nutrient Agar were procured from Sigma-Aldrich. All chemicals were viable status and they were made use of with no additional refinement. Milipure Water was used in the entire experimental work. The plant Ocimum sanctum L. (Tulsi) was obtained from RPRC (Regional Plant Research Centre) Bhubaneswar, Odisha, India and they were grown in earthen pots of School of Biotechnology

*Corresponding author: Birendra K Bindhani, School of Biotechnology KIIT University, Bhubaneswar, Odisha, India, Tel: 06742740326; E-mail: drbindhani@gmail.com

Received August 12, 2015; Accepted October 09, 2015; Published October 19 2015

Citation: Bindhani BK, Panigrahi AK (2015) Biosynthesis and Characterization of Silver Nanoparticles (SNPs) by using Leaf Extracts of Ocimum Sanctum L (Tulsi) and Study of its Antibacterial Activities. J Nanomed Nanotechnol S6: 008. doi:10.4172/2157-7439.S6-008

Copyright: (c) 2015 Bindhani BK, et al. This is an open-access article distributed under the terms of the Creative Commons Attribution License, which permits unrestricted use, distribution, and reproduction in any medium, provided the original author and source are credited. 
Citation: Bindhani BK, Panigrahi AK (2015) Biosynthesis and Characterization of Silver Nanoparticles (SNPs) by using Leaf Extracts of Ocimum Sanctum L (Tulsi) and Study of its Antibacterial Activities. J Nanomed Nanotechnol S6: 008. doi:10.4172/2157-7439.S6-008

Page 2 of 5

garden, KIIT University, Bhubaneswar, Odisha, India.

\section{Plant material collection}

Ocimum sanctum L. leaves were taken from the School of Biotechnology garden, Bhubaneswar, Odisha India. Then, leaves of Ocimum sanctum were air dried at least 10 days by using hot air oven at $60^{\circ} \mathrm{C}$ for $24 \mathrm{~h}$ to $48 \mathrm{~h}$. After that, leaves were ground to a fine powder form using dried leaves.

\section{Solvent extraction}

The air dried Ocimum sanctum L. leaves were milled to obtain a coarse powder. About $100 \mathrm{~g}$ of dry powders were taken with water at room temperature using soxhlet apparatus for 8 hours or the extraction was maintaind until the liquid was apparent. Then extraction was filtered and concentrated dry mass was done using vacuum. Thereafter, the extraction was air dried and aqueous extracts as done earlier were in the same way filtered and concentrated under vacuum. This crude extract was stored at $4^{\circ} \mathrm{C}$ in air tight bottles after diluted with $5 \%$ of DMSO to make the final volume one-tenth of the original volume for further studies.

\section{Synthesis of silver nanoparticles (SNPs)}

For synthesis of Silver nanoparticles (SNPs), $5 \mathrm{ml}$ of leaf extracts of Ocimum sanctum L. was added with $100 \mathrm{ml}$ of $1 \times 10^{-3} \mathrm{M}$ aqueous $\mathrm{AgNO}_{3}$ solution and it was stirred on the magnetic stirrer at room temperature. After 0 minute of reaction of the yellow colour mixture of $\mathrm{AgNO}_{3}$ solution with leaf extract was changed black suspended mixture very rapidly at room temperature just after 2 minutes. It was observed that the biosynthesis of SNPs using leaf extracts of Ocimum sanctum was taken place very rapidly than the other plants leaf [39]. The leaf extracts of Ocimum sanctum and concentrations of $\mathrm{AgNO}_{3}$ solution were also wide-ranging at $5 \%$ to $10 \%$ and 1 to $4 \mathrm{mM}$ by volume, respectively. The formation of SNPs was confirmed by UV-vis spectra as it showed strong SPR (showed strong surface plasmon resonance) band at $\sim 440 \mathrm{~nm}$. Futher, SNPs obtained from leaf extracts of Ocimum sanctum were centrifuged at 15,000 for 5 minutes and then dispersed in sterile distilled water to get free of any ungraceful biological materials. The procedure was based on phenol group (i.e., Eugenol) present in plant extract and reduced to form silver nanoparticles which was shown schematically (Figure 1).

\section{Techniques used for characterization}

The different techniques were used to characterized the SNPs such as UV-Vis (Shimadzu, Model: UV-1601, Kyoto, Japan) used to know the band at nanometer, X-ray diffractometer (Shimadzu, XRD6000 ) used to determine the crystallinity structures of SNPs, FT-IR (Fourier Transform Infrared) from a BIORAD-FTS-7PC type FTIR

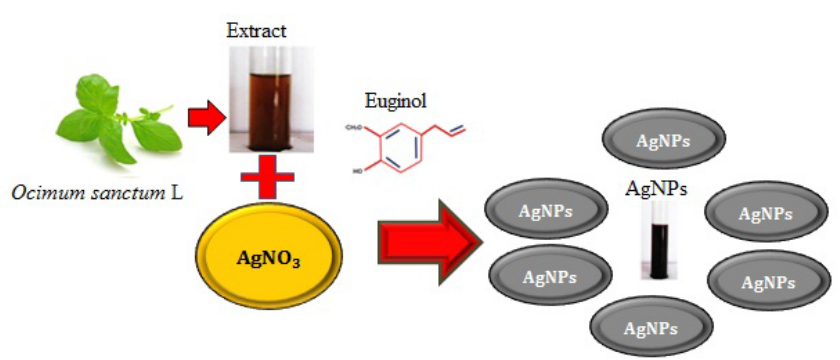

Figure 1: Schematically Representation of Synthesis of AgNPs using Ocimum sanctum $\mathrm{L}$. leaf extracts.

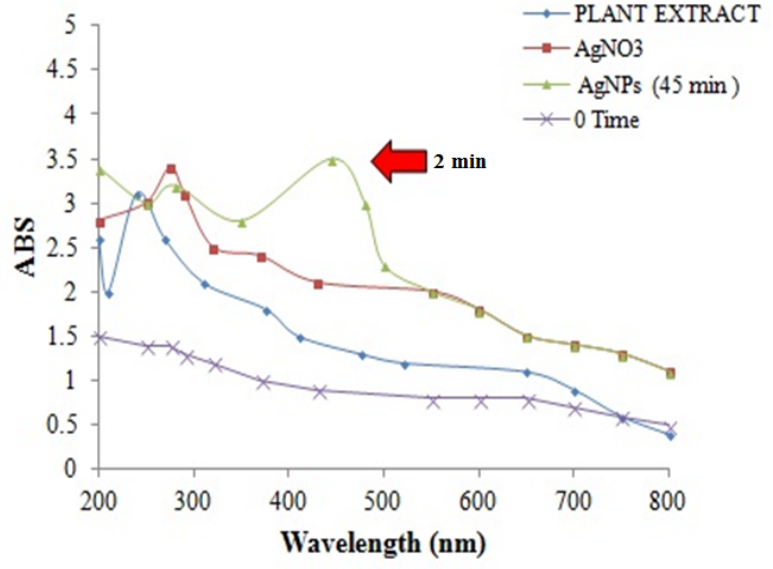

Figure 2: UV-Visible Absorption Spectra of AgNPs.

spectrophotometer which was used in the range 4,000 to $400 \mathrm{~cm}^{-1}$ by $\mathrm{KBr}$ pellet method for Ocimum sanctum leaf extract powder and SNPs. TEM (Philips CM-10) analysis was carried out to confirm the images of specimen by magnified focus on imaging device.

\section{Test of microorganisms}

Antibacterial activity: The bacterial strains studied were Enterobacter cloacae, Staphylococcus aureus, Staphylococcus aemolytius, Pseudomonas aeruginosa Proteus mirabilis and Proteus vulgaris. All microorganisms were maintained at $4^{\circ} \mathrm{C}$ and were obtained from Department of Botany, Berhampur University, Odisha, India.

Antimicrobial activity: The antimicrobial activity was carried out by disc diffusion method. The MHA (Mueller Hinton Agar) was used to screen the antimicrobial activity in vitro. The sterilized Petri plates containing $15 \mathrm{ml}$ of molten media of MHA were prepared and allowed to solidify for 5 minutes. Then, $0.1 \%$ inoculums suspensions were swabbed equally and permitted to dry for 5 minutes. The test extract approximately $50 \mu \mathrm{l}$ was loaded on $0.5 \mathrm{~cm}$ sterile disc to be found on the surface medium which was permitted to diffuse for 5 minutes and they were incubated at $37^{\circ} \mathrm{C}$ for $24 \mathrm{hr}$. The inhibition zone was formed in the region of the disc after 24 hours of incubation and it was measured by transparent ruler in millimeter. The negative controls were retained against each bacterial strain using pure solvents as an alternative of extract. The results of zone diameter were tabulated after substracted control zones from the test zones. For positive control, one antibiotic, namely Cefotaxime $(30 \mathrm{mcg} / \mathrm{disc})$ was used and it was performed in triplicate.

\section{Results}

\section{UV-vis absorbance}

The silver nitrate solution $\left(\mathrm{AgNO}_{3}\right)$ was mixed with leaf extracts of Ocimum sanctum showed change of brown colour from transparent solution which confirmed the synthesis of silver nanoparticles. This change of colour was due to the excitation of surface vibration by the silver nanoparticles. The reaction mixture was determined by UVvis from 0 till $45 \mathrm{~min}$ and formed surface plasmon resonace of SNPs peak centered near $440 \mathrm{~nm}$ (Figure 2) which indicated the reduction of $\mathrm{AgNO}_{3}$ into SNPs. This biosynthesis of silver nanoparticles was completed with 2 minutes at room temperature after reduction of $\mathrm{AgNO}_{3}$ into SNPs. 
Citation: Bindhani BK, Panigrahi AK (2015) Biosynthesis and Characterization of Silver Nanoparticles (SNPs) by using Leaf Extracts of Ocimum Sanctum L (Tulsi) and Study of its Antibacterial Activities. J Nanomed Nanotechnol S6: 008. doi:10.4172/2157-7439.S6-008

\section{$\mathrm{X}$-ray diffraction $(\mathrm{XRD})$ studies}

The crytalline nature of SNPs was confirmed by the X-ray diffraction analysis. The number of Bragg reflections was showed due to the face-centered cubic structure of silver by the analysis of X-ray diffraction. In this experiment, it was confirmed the SNPs in the form of nanocrystals due to the peak at $2 \theta$ values of $38.28^{\circ}, 44.04^{\circ}, 64.34^{\circ}$ and $77.28^{\circ}$ corresponding to (111), (200), (220) and (311) Bragg reflections (Figure 3 ) respectively on the basis of face-centered cubic structure of silver. This result confirmed the formation of SNPs by the reduction of $\mathrm{Ag}^{+}$ions with leaf extract of Ocimum sanctum which is crystalline in nature. The average crystalline size around $18 \mathrm{~nm}$ of silver nanoparticles was confirmed through our green methods of synthesis. It was calculated by using the Debye-Scherrer's equation [22,25]:

$$
D=\frac{K \lambda}{\beta \cos \theta}
$$

Where $\mathrm{D}$ is the crystallite size of AgNPs, $\lambda$ is the wavelength of the $\mathrm{X}$-ray source $(0.1541 \mathrm{~nm})$ used in XRD, $\beta$ is the full width at half maximum of the diffraction peak, $\mathrm{K}$ is the Scherrer constant with a value from 0.9 to 1 , and $\theta$ is the Bragg angle.

\section{FT-IR spectra of biosynthesized silver nanoparticles}

The results of biosynthesized silver nanoparticles was studied by FT-IR and showed clear absorption peaks located 3,411, 1,606, 1,554, and $1,406 \mathrm{~cm}^{-1}$ (Figure 4). The different absorption peaks like at 1,606

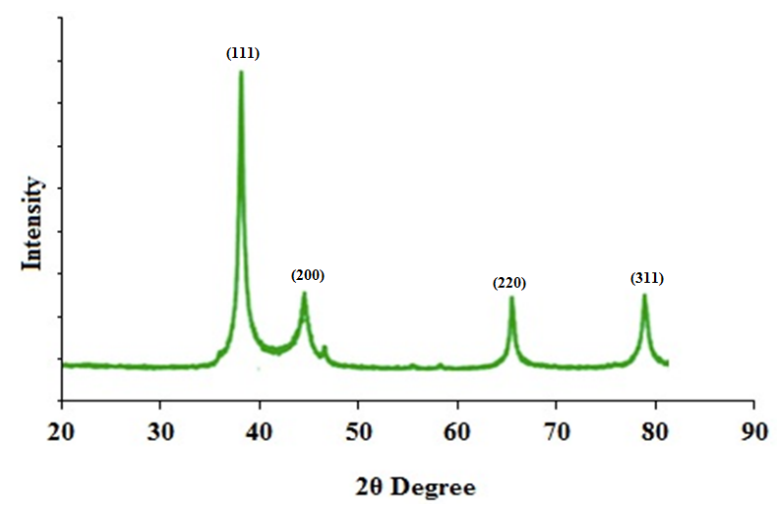

Figure 3: Representative XRD profile of AgNPs.

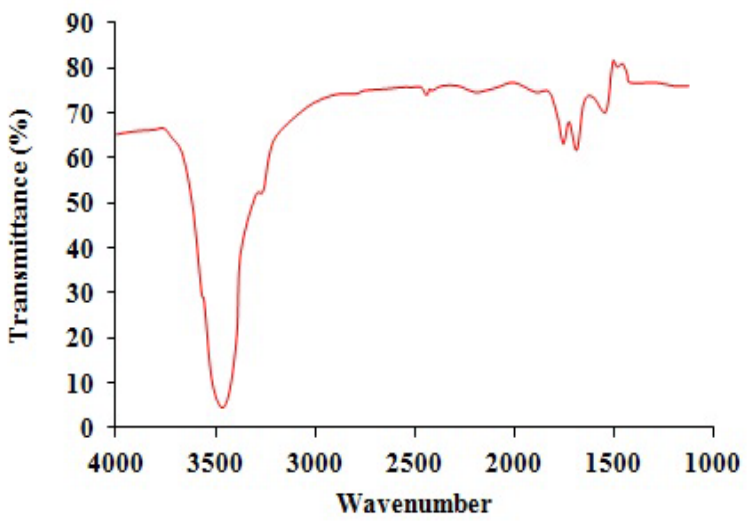

Figure 4: FTIR Spectrum of AgNPs.

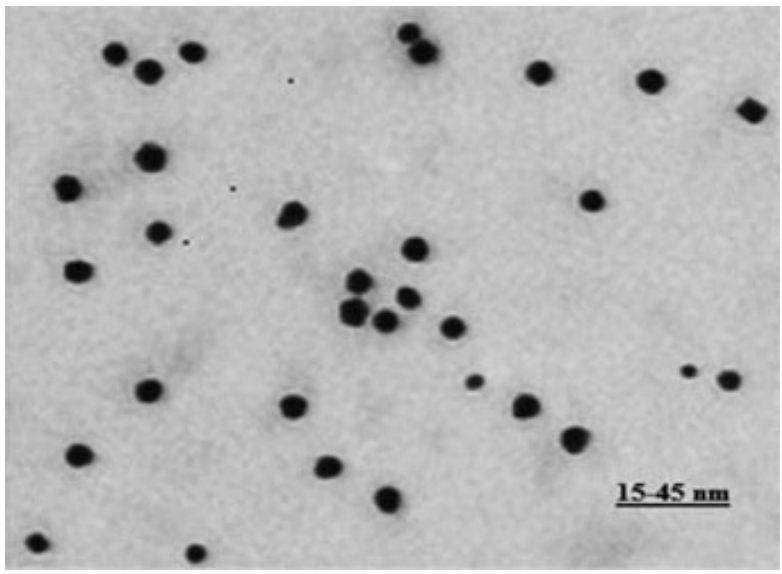

Figure 5: TEM micrograph of AgNPs synthesized by the reaction of 1 $\mathrm{mM}$ silver nitrate with Ocimum sanctum $\mathrm{L}$. leaf extract.

$\mathrm{cm}^{-1}$ which perhaps assigned to the amide I bond of proteins take place from carbonyl stretching in proteins and peak at $3,411 \mathrm{~cm}^{-1}$ possibly assigned to $\mathrm{OH}$ stretching in alcohols and phenolic compounds. However, the native proteins was closed in the absorption peak at $1,606 \mathrm{~cm}^{-1}$ by the interactions of SNPs through biosynthesis and the secondary structure was not affected for the period of reaction with $\mathrm{Ag}^{+}$ ions or after binding with $\mathrm{Ag}^{0}$ nanoparticles. This study was confirmed that the carbonyl group of amino acid residues has a strong binding ability with silver, signifying the creation of covering layers of SNPs and performing as a capping mediator to avoid agglomeration and give strength to the medium. These findings corroborate the occurrence of probable proteins performing as reducing and stabilizing agents [25].

\section{TEM (Transmission Electron Microscope)}

The TEM study confirmed that the morphology of nanoparticles was mainly spherical but some were may be oval and/or elliptical in shape and size of about 15-45 nm (Figure 5). These variations are common in biological synthesized nanoparticles. The edges of nanoparticles mainly lighter than the centres were visible due to proteins of biomolecules capped with SNPs. This study indicated that there was about $75 \%$ nanoparicles size ranges from $5 \mathrm{~nm}$ to $30 \mathrm{~nm}$ of the total particles observed.

\section{Bactericidal activity of silver nanoparticles}

The results of antimicrobial activity were shown in Table 1. Zone of inhibition was observed with the crude extract and different concentrations $(20 \mu \mathrm{g}, 40 \mu \mathrm{g}, 60 \mu \mathrm{g}$ and $80 \mu \mathrm{g})$ of silver nanoparticles against three gram-positive bacteria (Staphylococcus aureus, Enterococcus cloacae, Streptococcush aemolytius) and three gramnegative bacteria (Pseudomonas aeruginosa, Proteus vulgaris, Proteus mirabilis). The antimicrobial activity of silver nanoparticles showed more activity than that of plant leaf extracts. In gram positive bacteria, Staphylococcus aureus, Enterococcus cloacae showed similar significant activity of $1.77 \pm 0.06$ at the concentration of $20 \mu \mathrm{g}$ than Streptococcus haemolytius and in gram negative bacteria, Proteus vulgaris showed best significant activity of $2.06 \pm 0.04$ at the similar concentration when compared to Pseudomonas aeruginosa and Proteus mirabilis. There are numerous concerning features which are still on the verge of experimental verification yet to be explored. 
Citation: Bindhani BK, Panigrahi AK (2015) Biosynthesis and Characterization of Silver Nanoparticles (SNPs) by using Leaf Extracts of Ocimum Sanctum L (Tulsi) and Study of its Antibacterial Activities. J Nanomed Nanotechnol S6: 008. doi:10.4172/2157-7439.S6-008

Page 4 of 5

\begin{tabular}{|c|c|c|c|c|c|c|c|}
\hline \multirow[t]{2}{*}{ Organisms } & \multirow{2}{*}{$\begin{array}{c}\text { Antibiotic } \\
\text { (Cefotaxime) }\end{array}$} & \multirow[t]{2}{*}{ Plant Extracts } & \multicolumn{4}{|c|}{ Zone of inhibition of AgNPs in cm } & \multirow[t]{2}{*}{$P$ value } \\
\hline & & & $20 \mu g$ & $40 \mu \mathrm{g}$ & $60 \mu \mathrm{g}$ & $80 \mu \mathrm{g}$ & \\
\hline Enterobacter cloacae & $2.74 \pm 0.03$ & $1.10 \pm 0.40$ & $1.77 \pm 0.06$ & $1.51 \pm 0.10$ & $1.31 \pm 0.10$ & $1.03 \pm 0.12$ & $0.008^{* *}$ \\
\hline Staphylococcus aureu & $2.31 \pm 0.4$ & $1.00 \pm 0.40$ & $1.77 \pm 0.06$ & $1.66 \pm 0.06$ & $1.33 \pm 0.06$ & $1.01 \pm 0.10$ & $0.031^{*}$ \\
\hline Streptococcus haemolytius & $2.12 \pm 0.01$ & $0.83 \pm 0.22$ & $1.67 \pm 0.12$ & $1.41 \pm 0.10$ & $1.24 \pm 0.06$ & $0.92 \pm 0.05$ & $0.015^{* *}$ \\
\hline Pseudomonas aeruginosa & $2.23 \pm 0.43$ & $0.63 \pm 0.16$ & $1.16 \pm 0.03$ & $1.11 \pm 0.10$ & $0.83 \pm 0.06$ & $0.83 \pm 0.05$ & $0.001^{* *}$ \\
\hline Proteus vulgaris & $2.84 \pm 0.05$ & $0.77 \pm 0.2$ & $2.06 \pm 0.04$ & $1.56 \pm 0.06$ & $1.21 \pm 0.10$ & $0.94 \pm 0.05$ & $0.026^{*}$ \\
\hline Proteus mirabilis & $2.36 \pm 0.11$ & $1.30 \pm 0.20$ & $1.75 \pm 0.13$ & $1.31 \pm 0.10$ & $1.23 \pm 0.06$ & $0.71 \pm 0.11$ & $0.020^{* *}$ \\
\hline
\end{tabular}

Values are mean \pm SD of three samples; *Significant at $1 \%$ Level; **Significant at $5 \%$ Level

Table 1: The Antibacterial Activity of AgNPs Synthesized using Leaves Extracts of Ocimum sanctum $\mathrm{L}$.

\section{Discussions}

Generally, different types of antioxidant metabolites and enzymes are found in plants and they are very much helpful to check the oxidative damage to cellular components. Like all other plants, Tulsi (Ocimum sanctum L.) contains various types of important nutrients, manganese, vitamin-C, Fiber and also includes beneficial plant phytochemicals (i.e., Eugenol) which have both anti-cancer and antioxidant properties [40,41]. These anti-oxidative complexes hold up or reduce the oxidation of molecules by inhibiting the initiation or propagation of oxidative chain reaction. The phenolic compounds of anti-oxidative activity is mostly due to their redox property which can take part in neutralizing and absorbing free radicals, quenching singlet, decomposing peroxides or triplet oxygen. So many reports have categorically revealed close connection among whole phenolic contents and anti-oxidative capacity [42]. The anti-oxidant action is the outcome of a mixture of dissimilar complexes having both antagonistic as well as synergistic effect. The anti-oxidant potential of eugenol due to its stabilized phenoxy radical, present in phenolic nucleus which can be readily forms extended side chain conjugation. The formation of eugenol catalyzes stable phenoxy radical can be determined by UV absorption [43]. The eugenol may serve an important anti-oxidant function due to its effective scavenge harmful radicals and restrain radiation induced oxidative reactions. This is extremely quality stabilized radical because of unpaired oxygen which may be delocalized across the entire molecules [43]. This is achievable due to eugenol act as a reducing agent and is oxidized by $\mathrm{AgNO}_{3}$, resulting in the formation of AgNPs. The different type of scavengers' capacity presents such as chlorogenic acids, caeffic acids, eugenol and rosemarinic acids which are more effective for free radicals than benzoic acid derivatives [44]. As a result the diverse types of anti-oxidants present in the Ocimum sanctum are unique in terms of its structure and function for trapping the various free radicals synergistically reduces the Ag metal ions. Additionally, unrelated antioxidants reacts each other for formation of a new anti-oxidant.

The formation of AgNPs after reduction of $\mathrm{Ag}^{+}$which was confirmed by the color changes with addition of leaf extracts of Ocimum sanctum $\mathrm{L}$. to $\mathrm{AgNO}_{3}$ solution. The synthesis and aggregation of AgNPs through the fall of time was supported the progress of latest absorbance bands at $444 \mathrm{~nm}$ [45]. It showed that the transfer of charges may be happened among the medium and the particles present in the solution. The efficiency of antioxidant perhaps assumed as a result of encapsulation of bioactive molecules lying on the spherical surface of AgNPs during the electrostatic attraction along with neutral or positively charged nanoparticles and negatively charged bioactive compounds ( $\left.\mathrm{COO}^{-}\right)$. The consequent effect of activity of antioxidant agent depends on the site of addition of metals. To use AgNPs against microbes in various fields, it is important and necessary to prepare AgNPs in a green environment [45]. In this study, we report a green method for the preparation of AgNPs which is environmentally benign and cost-effective.

\section{Conclusion}

In conclusion a simple, fast and economical biological procedure introduced to synthesize silver nanoparticles using Ocimum sanctum L. leaf extract. The spectroscopic characterization of silver particles by UV-Visible, XRD, FTIR and TEM supports the stability of the biosynthesized nanoparticles. The extract of Ocimum sanctum L. was used as a reducing and capping agent. The SNPs were found to have wider antimicrobial activity in gram negative than gram positive organisms. The antibacterial activity of SNPs concluded that the silver nanoparticles showed significant antibacterial activity against Enterobacter cloacae, Staphylococcus aureu, Streptococcush aemolytius, Pseudomonas aeruginosa, Proteus vulgaris, Proteus mirabilis whereas less activity against Pseudomonas aeruginosa was observed.

\section{Acknowledgments}

The authors would like to thank Berhampur University, Odisha, India and KIIT University, Odisha, India for providing the opportunity to carry out this research work.

\section{References}

1. Conway T, Creecy JP, Maddox SM, Grissom JE, Conkle TL, et al. (2014) Unprecedented high-resolution view of bacterial operon architecture revealed by RNA sequencing. MBio 5: e01442-01414

2. Somboon T, Ochiai J, Treesuwan W, Gleeson MP, Hannongbua S, et al. (2014) Mechanistic insights into the catalytic reaction of plant allene oxide synthase (pAOS) via QM and QM/MM calculations. J Mol Graph Model 52: 20-29.

3. Majumdar S, Peralta-Videa JR, Bandyopadhyay S, Castillo-Michel H Hernandez-Viezcas JA, et al. (2014) Exposure of cerium oxide nanoparticles to kidney bean shows disturbance in the plant defense mechanisms. $\mathrm{J}$ Hazard Mater 278: 279-287.

4. Pillai K, Navarro Arzate F, Zhang W, Renneckar S (2014) Towards biomimicking wood: fabricated free-standing films of Nanocellulose, Lignin, and a synthetic polycation. J Vis Exp .

5. Tilbrook K, Poirier Y, Gebbie L, Schenk PM, Mc Qualter RB, et al. (2014) Reduced peroxisomal citrate synthase activity increases substrate availability for polyhydroxyalkanoate biosynthesis in plant peroxisomes. Plant Biotechno J 12:1044-1052.

6. Morris DS, Prevelige PE (2014) The role of the coat protein A-domain in p22 bacteriophage maturation. Viruses 6: 2708-2722

7. Cho IH, Irudayaraj J (2013) In-situ immuno-gold nanoparticle network ELISA biosensors for pathogen detection. Int J Food Microbiol 164: 70-75.

8. Sato K, Kitamori T (2004) Integration of an immunoassay system into a microchip for high-throughput assay. J Nanosci Nanotechnol 4: 575-579.

9. Levy I, Shoseyov O (2004) Cross bridging proteins in nature and their utilization in bio- and nanotechnology. Curr Protein Pept Sci 5: 33-49.

10. Wang H, Ke F, Mararenko A, Wei Z, Banerjee P, et al. (2014) Responsive Polymer-flurorescent carbon nanoparticle hybrid nanogels for optical 
Citation: Bindhani BK, Panigrahi AK (2015) Biosynthesis and Characterization of Silver Nanoparticles (SNPs) by using Leaf Extracts of Ocimum Sanctum L (Tulsi) and Study of its Antibacterial Activities. J Nanomed Nanotechnol S6: 008. doi:10.4172/2157-7439.S6-008

Page 5 of 5

temperature sensing, near-infrared light-responsive drug release and tumor cell imaging. Nanoscale 6: 7443-7452.

11. Xia Y, Chen Z, Zhang Z, Fang X, Liang G (2014) A nontoxic and low-cost hydrothermal route for synthesis of hierarchical Cu2ZnSnS4 particles. Nanoscale Res Lett 9: 208.

12. Faramarzi MA, Sadighi A (2013) Insights into biogenic and chemical production of inorganic nanomaterials and nanostructures. Adv Colloid Interface Sci 189190: $1-20$

13. Yang HW, Hua MY, Liu HL, Huang CY, Wei KC (2012) Potential of magnetic nanoparticles for targeted drug delivery. Nanotechnol Sci Appl 5: 73-86.

14. Schrand AM, Dai L, Schlager JJ, Hussain SM (2012) Toxicity testing of nanomaterials. Adv Exp Med Biol 745: 58-75.

15. Borase HP, Salunke BK, Salunkhe RB, Patil CD, Hallsworth JE, et al. (2014) Plant extract: a promising biomatrix for ecofriendly, controlled synthesis of silver nanoparticles. Appl Biochem Biotechnol 173: 1-29.

16. Hulkoti NI, Taranath TC (2014) Biosynthesis of nanoparticles using microbes- a review. Colloids Surf B Biointerfaces 121: 474-483.

17. Kolmas J, Groszyk E, Kwiatkowska-RÃ $\tilde{A}^{3} \AA^{1} / 4 y c k a \quad D(2014)$ Substituted hydroxyapatites with antibacterial properties. Biomed Res Int 2014: 178123.

18. Poulose S, Panda T, Nair PP, Théodore T (2014) Biosynthesis of silver nanoparticles. J Nanosci Nanotechnol 14: 2038-2049.

19. Mondal S, Mirdha BR, Mahapatra SC (2009) The science behind sacredness of Tulsi (Ocimum sanctum Linn.). Indian J Physiol Pharmacol 53: 291-306.

20. Hemaiswarya S, Kruthiventi AK, Doble M (2008) Synergism between natural products and antibiotics against infectious diseases. Phytomedicine 15: 639652.

21. VS Raseetha, SF Cheng, $\mathrm{CH}$ Chuah (2009) Comparative study of volatile compounds from genus Ocimum. Am J Appl Sci 6: 523-528

22. Amin M, Anwar F, Janjua MR, Iqbal MA, Rashid U (2012) Green Synthesis of silver nanoparticles through reduction with Solanum xanthocarpum L. Berry Extract: Characterization, Antimicrobial and Urease Inhibitory Activities agains Helicobacter pylori. Int J Mol Sci 13: 9923-9941.

23. Loo YY, Chieng BW, Nishibuchi M, Radu S (2012) Synthesis of silver nanoparticles by using tea leaf extract from Camellia sinensis. Int $J$ Nanomedicine 7: 4263-4267.

24. Shameli K, Bin Ahmad M, Jaffar Al-Mulla EA, Ibrahim NA, Shabanzadeh $P$, et al. (2012) Green biosynthesis of silver nanoparticles using Callicarpa maingay stem bark extraction. Molecules 17: 8506-8517.

25. Kumar V, Yadav SK (2012) Synthesis of different-sized silver nanoparticles by simply varying reaction conditions with leaf extracts of Bauhinia variegata $L$. IET Nanobiotechnol 6: 1-8.

26. Mohan Kumar K, Sinha M, Mandal BK, Ghosh AR., Siva Kumar K, et al. (2012) Green synthesis of silver nanoparticles using Terminalia chebula extract at room temperature and their antimicrobial studies. Spectrochim Acta part A Mol Biomol Spectrosc 91: 228 - 233.

27. Vijayaraghavan K, Nalini SP, Prakash NU, Madhankumar D (2012) One step green synthesis of silver nano/microparticles using extracts of Trachyspermum ammi and Papaver somniferum. Colloids Surf B Biointerfaces 94: 114-117.

28. Guidelli EJ, Ramos AP, Zaniquelli ME, Baffa O (2011) Green synthesis of colloidal silver nanoparticles using natural rubber latex extracted from Hevea brasiliensis. Spectrochim Acta a Mol Biomol Spectrosc 82:140 - 145.

29. Elavazhagan T, Arunachalam KD (2011) Memecylon edule leaf extract mediated green synthesis of silver and gold nanoparticles. Int J Nanomedicine 6: 1265-1278.

30. Zhang Y, Yang D, Kong Y, Wang X, Pandoli O, et al. (2010) Synergetic antibacterial effects of silver nanoparticles @ Aloe vera prepared via a green method. Nano Biomed Eng 2: 252-257.

31. Markowska K, Grudniak AM, Krawczyk K, Wróbel I, Wolska KI (2014) Modulation of antibiotic resistance and induction of a stress response in Pseudomonas aeruginosa by silver nanoparticles. J Med Microbiol 63: 849-854.

32. Martínez-Gutierrez F, Thi EP, Silverman JM, de Oliveira CC, Svensson SL et al. (2012) Antibacterial activity, inflammatory response, coagulation and cytotoxicity effects of silver nanoparticles. Nanomedicine 8: 328-336.

33. Shin $\mathrm{SH}$, Ye MK (2011) The effect of nano-silver on the activation of nasal polyp epithelial cells by Alternaria, Der P1 and staphylococcal enterotoxin B. Int Immunopharmacol 11: 1691-1696.

34. Kemp MM, Kumar A, Mousa S, Dyskin E, Yalcin M, et al. (2009) Gold and silver nanoparticles conjugated with heparin derivative possess anti-angiogenesis properties. Nanotechnolgy 20: 455104.

35. Deb S, Raja SO, Dasgupta AK, Sarkar R, Chattopadhyay AP, et al. (2012) Surface tunability of nanoparticles in modulating platelet functions. Blood Cells Mol Dis 48: 36-44.

36. Fernandez A, Picouet P, Lloret E (2010) Reduction of the spoilage-related micro flora in absorbent pads by silver nanotechnology during modified atmosphere packaging of beef meet. J Food Prot 73: 2263-2269.

37. An C, Wang J, Liu J, Wang S, Sun Y (2013) Hollow Agl:Ag nanoframes as solar photocatalysts for hydrogen generation from water reduction. ChemSusChem 6: 1931-1937.

38. Gogoi N, Chowdhury D (2014) In-situ and ex-situ chitosan-silver nanoparticle composite: comparison of storage/release and catalytic properties. J Nanosci Nanotechnol 14: 4147-4155.

39. Rout A, Jena PK, Sahoo D, Parida UK, Bindhani BK (2014) Green Synthesis and Characterization of Silver Nanoparticles for Antimicrobial Activity Against Burn Wounds Contaminating Bacteria. International Journal of Nanoscience 13: 1450010.

40. Mahajan N, Rawal S, Verma M, Poddar M, Alok S (2013) A phytopharmacological overview on Ocimum species with special emphasis on Ocimum sanctum. Biomedicine \& Preventive Nutrition 3: 185-192

41. Yanpallewar SU, Rai S, Mohan K, Acharya SB (2004) Evaluation of antioxidant and neuroprotective effect of Ocimum sanctum on transient cerebral ischemia and long-term cerebral hypoperfusion. Pharmacology Biochemistry and Behavior 79: 155-164.

42. Geetha RK, Vasudevan DM (2004) Inhibition of lipid peroxidation by botanica extracts of Ocimum sanctum: in vivo and in vitro studies. Life Sci 76: 21-28.

43. Prakash P, Gupta N (2005) Therapeutic uses of Ocimum sanctum Linn (Tulsi) with a note on eugenol and its pharmacological actions: a short review. Indian J Physiol Pharmacol 49: 125-131.

44. Ramesh B, Satakopan VN (2010) Antioxidant Activities of Hydroalcoholic Extract of Ocimum sanctum Against Cadmium Induced Toxicity in Rats. Indian J Clin Biochem 25: 307-310.

45. Banala RR, Nagati VB, Karnati PR (2015) Green synthesis and characterization of Carica papaya leaf extract coated silver nanoparticles through X-ray diffraction, electron microscopy and evaluation of bactericidal properties. Saudi J Biol Sci 22: 637-644 